Revista Digital Universitaria

Vol. 23, Núm. 1, enero-febrero 2022

\title{
SUAyED como una oportunidad para alcanzar tus sueños
}

\author{
Grisel Lugo Bolaños
}

\section{Resumen}

En el siguiente testimonio se abordan las facilidades de estudiar Pedagogía en el sistema de educación a distancia de la Facultad de Filosofía y Letras de la unam, destacando la flexibilidad de horarios, la accesibilidad, la calidad y el sentido de pertenencia universitario, a partir de la experiencia de una estudiante de la generación 2018.

Palabras clave: Pedagogía, educación a distancia, comunidad universitaria.

\section{Open and Distance Education University System as an opportunity to REACH YOUR DREAMS}

\begin{abstract}
On the following text it is described the advantages of studying Pedagogy on the Long-distance education system on the Philosophy and Literature Department at the unam, Remarking the schedule flexibility, the easy access to bibliographic resources, the teaching quality, and the college pride. From a 2018 Class student.
\end{abstract}

Keywords: Pedagogy, Long distance education, university community. 
Maestra en Ciencias del Sistema Nervioso Central egresada de la Universitat Rovira i Virgili de Tarragona, España. Cuenta con una amplia experiencia en el área de enseñanza en ciencias a nivel educativo básico y media superior.

Realizó sus estudios de Licenciatura como Química Farmacéutica Biológica en la Facultad de Química de la Universidad Nacional Autónoma de México, misma en la que se diplomó en aprendizajes claves y competencias fundamentales para la enseñanza de las ciencias naturales. Actualmente es Profesional de Enseña por México, una organización sin fines de lucro que busca resolver la inequidad educativa en el país.

$\mathrm{H}$ ola, mi nombre es Grisel. Soy licenciada en Química Farmacéutica Biológica por la UNAM, cuento con una Maestría en Ciencias del Sistema Nervioso por la uRv y desde el 2018, curso la carrera de Pedagogía en modalidad a distancia en la Facultad de Filosofía y Letras de la unam. Seguramente te estarás preguntando por qué decidí estudiar Pedagogía como segunda carrera. La razón es que cuando llegó el momento de dempeñarme profesionalmente me di cuenta que la docencia era mi verdadera vocación y que si quería hacerlo bien, necesitaba las herramientas adecuadas. Sin embargo, en esta ocasión tenía una limitante, que era poder estudiar y trabajar al mismo tiempo.

Para mi, el Sistema Universidad Abierta y Educación a Distancia (SUAYED) me ha dado la oportunidad de tener la formación integral que buscaba y seguir trabajando a la par de mis estudios. Esto es posible porque una de las grandes ventajas de estudiar a distancia es que todo se lleva a cabo mediante una plataforma en línea, por lo que cada estudiante puede gestionar a qué hora del día y dónde hacer sus tareas sin que se interpongan con sus demás actividades. Puedes estar en cualquier parte del mundo y eso no interfiere con tus estudios. Lo único que necesitas es tu material de lectura y un equipo con procesador de textos; es decir, la educación a distancia es una opción económica y accesible. Es importante destacar que dicha modalidad requiere de una alta autonomía en el aprendizaje de cada estudiante, pero esto no quiere decir que no te acompañarán en el proceso. La comunicación con el personal docente es continua; te ofrecen retroalimentación de tus actividades, responden tus dudas, existen foros de discusión entre colegas en cada materia e incluso, hay la posibilidad de hacer videollamadas con el profesor o la profesora y/o los compañeros y las compañeras de clase, lo que propicia un ambiente de aprendizaje agradable. 
Otro punto que me gustaría mencionar que ha sido de mucha utilidad a la hora de organizar mis ocupaciones laborales junto con las escolares, es que el material de lectura para las actividades de las clases te lo proporcionan de manera conjunta en una antología por materia y gracias a esto, puedes optimizar tus tiempos de búsqueda bibliográfica. Estas antologías tienen un costo, pero no es restrictivo hacer uso sólo de ellas, porque como estudiantes también tenemos acceso a las bibliotecas digitales de la unAm, la cual cuenta con muchos recursos en línea.

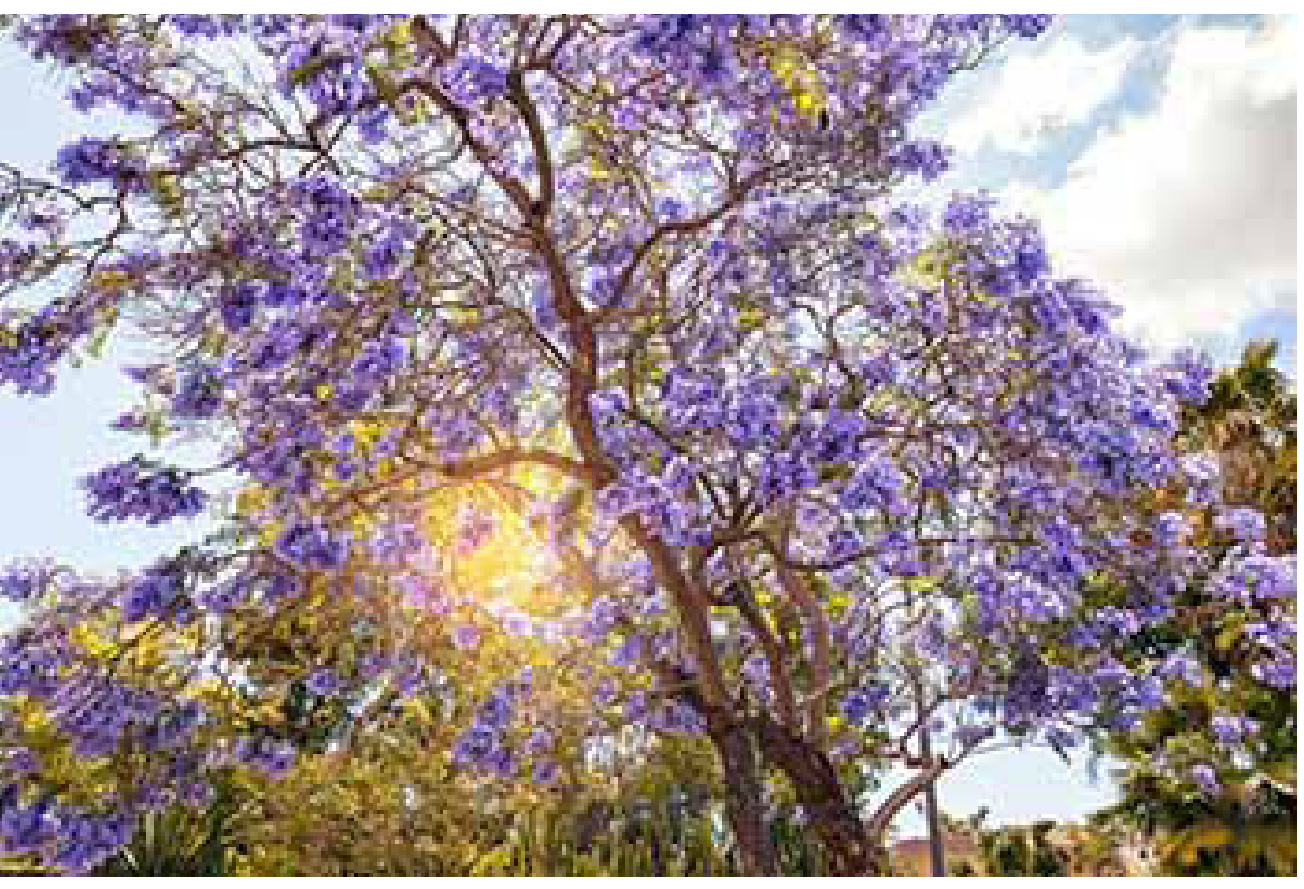

En cada materia se busca una evaluación auténtica que fomente un pensamiento crítico y reflexivo, haciéndonos más conscientes de nuestro contexto para poder aplicar los conocimientos adquiridos en nuestro día a día y tener aprendizajes significativos. Puedo decir que lo que he aprendido hasta ahora me ha ayudado a desempeñarme mejor en mi campo de trabajo. La flexibilidad del Sistema Universidad Abierta y Educación a Distancia en definitiva me permite ser una mejor profesionista y cumplir satisfactoriamente con mi vocación docente.

Algo que me sorprendió de forma grata es la comunidad que existe entre los estudiantes del sistema de educación a distancia. Puedes contactar directamente a tus compañeros y compañeras de clase ya sea por medio de la plataforma o formar parte de los diversos grupos en redes sociales, con el fin de resolver dudas, compartir información relevante de la carrera o trabajar de manera colaborativa. La distancia no es ninguna restricción para formar relaciones positivas con tus colegas, pero depende de ti involucrarte de forma activa y constante para formar estos lazos; siempre que te acerques a la comunidad educativa, te aseguro que recibirás respuestas agradables; sólo es cuestión que te animes a hacerlo.

Como podrás reconocer hasta ahora, la educación a distancia es una opción accesible, flexible, económica y de calidad. Mi experiencia en esta modalidad ha sido muy buena. En lo particular, gracias a que existen alternativas de estudio como ésta, es por lo que he podido seguir mi formación como profesionista de la educación sin tener que acudir a un campus universitario. Además, puedo seguir acumulando experiencia en el campo laboral mientras estudio. Actualmente soy líder educativo en "Enseña por México", en donde mis habilidades en las ciencias experimentales así como en las ciencias sociales, se complementan de manera efectiva. 
Considero que el haber decidido estudiar Pedagogía a distancia es una de las mejores decisiones que he tomado en mi vida. Estudiar en la universidad es toda una experiencia académica, cultural y deportiva que te da sentido de pertenencia dentro de la comunidad universitaria, sin olvidar que te ofrece una oportunidad para cumplir tus sueños o propósitos, siempre y cuando estés dispuesta o dispuesto a trabajar por ellos.

\section{Sitios de interés}

* Sitio web de la Licenciatura en Pedagogía en la modalidad de Sistema de Universidad Abierta y Educación a Distancia que se imparte en la Facultad de Filosofía y Letras de la unAm.

* Página principal de la Coordinación de Universidad Abierta, Innovación Educativa y Educación a Distancia (CUAIEed)

* Página principal de la Biblioteca Digital unam

* Sitio Web de Enseña por México

\section{Cómo CITAR ESTE ARTículo}

* Lugo Bolaños, Grisel. (2022, enero-febrero). SUAyED como una oportunidad para alcanzar tus sueños. Revista Digital Universitaria (RDU), 23(1). http://doi.org/10.22201/ cuaieed.16076079e.2022.23.1.11 